\title{
Epidemiology of back pain in the teaching districts of B. P. Koirala Institute of Health Sciences
}

\author{
B P Shrestha ${ }^{1}$, S Niraula ${ }^{2}$, G P Khanal ${ }^{1}$, N K Karn ${ }^{1}$, \\ P Chaudhary $^{1}$ R Rijal $^{1}$, R Maharjan ${ }^{1}$ \\ ${ }^{1}$ Department of Orthopaedics, ${ }^{2}$ School of Public Health \& Department of Community Medicine \\ B.P.Koirala Institute of Health Sciences
}

\begin{abstract}
Introduction: The prevalence of back pain is very high in the general population but little is known about the predictors of back pain in the general population. Though certain risk factors have been associated with back pain, these are mentioned in Western literature. It is not known how much of these hold true for a developing country like Nepal. Objective: To estimate the prevalence of back pain in the Teaching Districts of B.P.Koirala Institute of Health Sciences and to identify predictors of back pain in the community. Materials and Methods: Three hundred and fourteen persons of eighteen years and above were included in this cross-sectional descriptive study conducted from January 2006 to December 2009 using pretested questionnaires. Results: The annual prevalence of back pain among males $(67.9 \%)$ and females $(74.3 \%)$ were similar $(\mathrm{P}>0.05)$ and the overall annual prevalence was $71 \%$. The highest prevalence of back pain was found in the age group of 31-40 years. Age, marriage and occupation were related significantly to the occurrence of back pain. The total duration of back pain in one year was less than 15 days in $73 \%$. The number of workdays lost was upto 5 in $81 \%$ of people with back pain. Conclusion: Back pain is a very common complaint among the adult population in the community. Population belonging to 31-50 age group, married status and farmers and labourers are more prone to have back pain. Gender, height and weight are not associated with back pain.
\end{abstract}

Keywords: back pain, predictors, community.

\section{Instroducation}

The high frequency occurrence of back pain and the magnitude of its impact on society explain the large number of epidemiologic studies. ${ }^{1}$ Hult estimates that upto $80 \%$ of the people are affected by backache at some time in their lives. ${ }^{2}$ Little information exists in the literature regarding the epidemiology of back pain in developing countries. ${ }^{3}$ Disorders of the lumbar spine are among the most

Address for correspondence

Dr Bikram Prasad Shrestha

Department of Orthopaedics

B.P.Koirala Institute of Health Sciences, Dharan

Email:bkrmstha@gmail.com common medical problems in western countries, affecting upto $80 \%$ of people at some time during their lives. ${ }^{4}$ Little is known about the predictors of low back pain in the general population. Though certain risk factors like smoking, obesity, driving, psychological stress, age, height and patterns of work especially heavy work have been associated with back pain, these are mentioned in Western literature. It is not known how much of these hold true for a developing country like Nepal.

The economic loss to the society and patients incurred as the result of backache in terms of work loss, work compensation and treatment is staggering. 
Frymoyer estimates that the direct medical and the indirect costs of backache are in the range of more than 50 billion US dollars per annum and could be as high as 100 billion dollars per annum at the extreme. ${ }^{5}$ In Nepal it is quite difficult to estimate the loss incurred due to work loss and because insurance is not done commonly, it is difficult to calculate work compensation. The main objective of this study was to estimate the prevalence of back pain and to identify the possible predictors of back pain in the Teaching Districts of B.P.Koirala Institute of Health Sciences which could be taken as representative of eastern Nepal.

\section{Methods}

This is a community based cross sectional study conducted from January 2006 to December 2009 in the Teaching Districts of B.P.Koirala Institute of Health Sciences which includes Ilam, Bhadrapur, Dhankuta, Inaruwa, Rangeli and Rajbiraj. Households in the periphery of the hospitals in each of the towns were selected randomly and pretested questionnaires were used to interview the available members of the family. A total of 314 persons were included in the study. The questionnaires included questions relating to variables like age, sex, marital status, number of children, occupation, height, weight and number of episodes of backache in the past one year from the date of interview.

The study was approved by the Ethical Review Board of the Institute. The study was funded by the Research Committee of B.P.Koirala Institute of Health Sciences.

The collected data were entered into computer through Microsoft Excel program. Using Epi Info 2000 software, the data were summarized by calculating frequencies and percentages for discrete variables and mean and standard deviations for continuous variables. The Chi square test was used to examine the significance of difference between the discrete variables and Mann-Whitney U test, a non-parametric test was applied to test the significance of difference amongst continuous variables. Alfa was set at 5\% level of significance.

\section{Results}

The study population consisted of 314 adults of 18 years and above with a mean age of $40.19 \pm 15.19$ years of which $162(51.6 \%)$ were males (mean age $=42.15 \pm 15.09$ years) and $152(48.4 \%)$ were females (mean age $=39.59 \pm 15.24$ years). The age ranged from 18 to 87 years. The prevalence of back pain among males was $67.9 \%$ and among females was $74.3 \%$ (Chi square $=1.58, \mathrm{~d} \mathrm{f}=1, \mathrm{P}>0.05$ ). The overall annual prevalence of back pain among both males and females was $71 \%$. Though the percentage of females having back pain was higher than that of males, the probability of significance shows that gender did not have significant relation to back pain.

The distribution of age group in relation to the presence or absence of back pain is shown in table 1. It shows that the highest prevalence of back pain is in the age group 31-40, closely followed by age group 41-50.

Table 1: Distribution of back pain according to age group

\begin{tabular}{|l|c|c|}
\hline $\begin{array}{l}\text { Age group } \\
\text { (years) }\end{array}$ & $\begin{array}{c}\text { Back pain } \\
\text { present }\end{array}$ & $\begin{array}{c}\text { Percentage out of } \\
\text { whole sample population }\end{array}$ \\
\hline $18-20$ & 6 & 1.91 \\
$21-30$ & 38 & 12.10 \\
$31-40$ & 63 & 20.00 \\
$41-50$ & 56 & 17.83 \\
$51-60$ & 32 & 10.19 \\
$>60$ & 28 & 8.92 \\
\hline Total & 223 & 71.00 \\
\hline
\end{tabular}

The means of age, height and weight of the persons having and not having back pain are shown in table 2. The table shows that only age had significant relation to occurrence of back pain. Younger the age the less is chance of having back pain.

Table 2: The relation of age, height and weight to back pain

\begin{tabular}{|l|l|c|c|c|c|c|}
\hline & Back pain & $\mathrm{N}$ & Mean \pm SD & t value & $\mathrm{d} \mathrm{f}$ & P value \\
\hline Age & Present & 223 & $43.74 \pm 15.071$ & 5.401 & 312 & $<0.001$ \\
(year) & Absent & 91 & $33.97 \pm 13.190$ & & & \\
\hline Height & Present & 223 & $158.39 \pm 9.670$ & -.911 & 312 & 0.363 \\
$(\mathrm{~cm})$ & Absent & 91 & $159.45 \pm 8.529$ & & & \\
\hline Weight & Present & 223 & $58.74 \pm 10.276$ & .918 & 312 & 0.359 \\
$(\mathrm{~kg})$ & Absent & 91 & $57.54 \pm 10.963$ & & & \\
\hline
\end{tabular}


Of all the study population interviewed, $279(88.85 \%)$ were married/widow/widower and 35(11.15\%) were unmarried. Among the married population, $76.0 \%$ of had back pain whereas only $31.4 \%$ of unmarried had back pain. (Chi-square $=29.99, \mathrm{P}<0.001)$. Marriage had a strong statistical correlation with back pain.

Of the 152 females, 19(12.5\%) had undergone one or more abortions. The prevalence of back pain among those with abortion was $78.9 \%$ and that among those without it $74.4 \%$. (Chi-square $=0.225$, $\mathrm{df}=1, \mathrm{P}>0.05$ ). Abortion did not have any significant relation to the presence or absence of back pain.

Among the study population, 246(78.9\%) were smokers and 66(21.1\%) were non-smokers. Among the non-smokers $69 \%$ had back pain and among the smokers $78.8 \%$ had back pain (Chi-square $=2.450, \mathrm{~d}$ $\mathrm{f}=1, \mathrm{P}>0.05$ ). Smoking did not have any significant association with back pain.

The common occupations in the study population were housewife (125), farmer/laborer (67), business (41), service (43), students (26) and others (12). Among these, the highest rate of back pain was found among the farmers/laborers $(85.1 \%)$ and the lowest among the students (30.8\%). The distribution of back pain among the various occupations is shown in table 3. The proportion of significance shows that occupation has a significant relation to the occurrence of back pain.

Table 3: The distribution of back pain according to occupation

\begin{tabular}{|l|l|l|l|l|l|}
\hline \multirow{2}{*}{ Profession } & \multicolumn{2}{|c|}{ Back pain } & Total & Chi-square & P value \\
& Present & Absent & & 27.972 & $<0.001$ \\
\hline Housewife & $91(72.8 \%)$ & $34(27.2 \%)$ & 125 & & \\
Farmer/laborer & $57(89.4 \%)$ & $10(10.6 \%)$ & 67 & & \\
Business & $27(65.9 \%)$ & $14(34.1 \%)$ & 41 & \\
Service & $32(74.4 \%)$ & $11(25.6 \%)$ & 43 & \\
Student & $8(30.8 \%)$ & $18(69.2 \%)$ & 26 & \\
Others & $8(66.7 \%)$ & $4(33.3 \%)$ & 12 & & \\
\hline Total & 223 & 91 & 314 & & \\
\hline
\end{tabular}

Of all the study population, $223(71 \%)$ had back pain. They were asked what they thought were the causes of their back pain. There were 295 responses; some of the respondents gave more than one cause. Excessive exertion was the most common (36.3\%) response. The other ones were lifting heavy weights (15.3\%), associated medical illness (14.2\%), general weakness $(13.9 \%)$, some trauma $(7.1 \%)$, menstruation $(0.7 \%)$, bad posture $(0.7 \%)$ and aging $(0.4 \%)$.

Of the 223 patients who had back pain, only $58.7 \%$ of respondents sought treatment, $41.3 \%$ did not.

The number of episodes of back pain in the past one year varied from one to more than 10. Among those who had back pain, there were one, two and three episodes in $22 \%, 29.6 \%$ and $18.8 \%$ respectively. Ten or more episodes of back pain were present in $1.8 \%$. Most of the patients with back pain had $1-5$ episodes $(87.4 \%)$.

The back pain in one year among those who had back pain lasted for upto 15 days in $70.9 \%$ and between 16 days to 30 days in $15.2 \%$. It was between 1 to 3 months in $9.9 \%$ and more than 3 months in $4 \%$ of the persons having back pain.

The severity of the pain was graded subjectively. Pain that did not disturb their work was considered mild, pain that was severe enough to disturb their work was considered moderate and pain that caused the patient to be bed ridden was labeled as severe. Mild, moderate and severe pains were experienced by $60.5 \%, 32.35 \%$ and $7.25 \%$ of the respondents respectively.

The number of workdays lost was less than 5 in $81 \%$ in the back pain group, between 6 to 10 days in 9.3\%. $7.4 \%$ lost between 11 to 30 days and $2.7 \%$ lost more than a month.

Only 131 persons (58.7\%) among those with back pain sought medical treatment. One of the questions to the interviewees who did not seek medical treatment was the reason for not doing so. The most common answer (71.3\%) was that it was because the pain was mild and self limiting. The other reasons 
for not seeking medical treatment were lack of time (18.1\%), medical services being too far away $(4.3 \%)$ and no money $(3 \%)$ respectively. There was no response from $3 \%$.

Amongst those who received treatment, the most common diagnosis for their problem made by their treating doctors was mechanical back pain (42.2\%). Others included degenerative aging $(9.5 \%)$, weakness $(6.9 \%)$, and trauma (5.2\%). Among the respondents who received treatment, $12.1 \%$ could not recall the diagnosis or no diagnosis was made in their cases.

Regarding the duration of treatment among those who sought medical treatment, it lasted for upto 15 days in $73 \%$, from 16 to 30 days in $14.2 \%$ and in $12.8 \%$ the treatment exceeded one month.

The response to treatment among the study population is shown in table 4 .

\section{Table 4: Response to treatment}

\begin{tabular}{|l|c|}
\hline $\begin{array}{l}\text { Response to treatment } \\
\text { in percentage of relief }\end{array}$ & $\begin{array}{c}\text { Percentage of population } \\
\text { with back pain }\end{array}$ \\
\hline Upto 25 & 3.7 \\
$26-50$ & 24.4 \\
$51-75$ & 23.8 \\
$76-100$ & 48.1 \\
\hline
\end{tabular}

\section{Discussion}

The annual prevalence of back pain in the study population of this study is $71 \%$, being slightly higher in females (74.3\%) as compared to males (67.9\%). This indeed is a very high prevalence. There are studies which estimate the lifetime occurrence of back pain in upto $80 \%$ of population. ${ }^{2-4}$ Similarly Frymoyer et al in their study entitled 'Risk factors in low back pain' have shown that during a lifetime, $70 \%$ of men will have at least one episode of back pain. ${ }^{6}$

In the general population, the incidence of back pain appears to be equally distributed between men and women. ${ }^{7}$ Our study also showed no correlation between gender and back pain.

We tried to find the association of age, height and weight with back pain. Age had a strong association with the occurrence of back pain. The group without back pain tended to be younger (43.74 years in back pain group as compared to 33.97 in no back pain group). Weight and height did not have any relation to the back pain. This is consistent with the study of Deyo RA et al in which they also did not find any strong correlation between height, weight, body build and the occurrence of back pain. ${ }^{8}$ Jacek A et al in their study on predictors of back pain in general population cohort found strong correlation between age, height and pattern of work (especially heavy work) in men only. They did not find weight as a significant factor in both men and women. ${ }^{9}$

Low back pain is most prevalent between the ages 35 and 55 years $^{7}$. The findings in our study is also similar as the most common age group was 31-40 years $(20 \%)$ followed closely by age group $41-50$ years $(17.83 \%)$.

In our study all married people including widow/ widower had significantly higher prevalence of back pain but it would be difficult to infer that marriage is associated with higher prevalence of back pain because married people are generally older than unmarried people and people with back pain tend to be older than those without back pain. The other studies do not mention any relation of marriage to back pain.

We tried to examine the relationship between abortion and back pain and found that though the occurrence of back pain was slightly higher among those who had undergone abortion it had no statistical significance. Many studies show that smoking is associated with back pain. ${ }^{6,8}$ Our study also showed higher prevalence of back pain among the smokers but statistically it was not significant. It may be because of small sample size. But Jacek et al also did not find any correlation between smoking and back pain. ${ }^{9}$ Smoking was not linked to back pain also in Manchester study conducted by Croft et al in $1999 .{ }^{10}$ The higher prevalence of back pain among the farmers and housewives can be understood. In our society especially in rural areas, farmers and housewives perform physical work more than non farming males. Acharya and Bennet in 1981 conducted a study in 8 villages of Nepal and found that Nepalese women spend 11.44 hours per day in working as compared to 8.34 hours per day for men. ${ }^{11}$ In a study performed by Pradhan A in 2003, the prevalence of back pain among those with long working hours (more than 7 hours) was $75.8 \%$ as compared to $48.8 \%$ among those with normal working hours (upto 7 hours). ${ }^{12}$ Kelsey et al in their study conducted in the United States stated that bulky objects and objects that required frequent lifting increase the incidence of back complaints. ${ }^{13}$ In our study, the lowest prevalence of back pain was found among students $(30.8 \%)$ which is understandable 
because they were not only young but also did not have to perform hard labour.

In our study, in $70.9 \%$ of those who had back pain, it lasted for upto 15 days. Another $15.2 \%$ had back pain for 16 to 30 days i.e. $86.1 \%$ had back pain lasting upto 30 days. This means that fortunately most of the people do not suffer beyond 30 days. This finding is somewhat similar to the findings of Tamar $\mathrm{J}$ et al who in their longitudinal community based study of low back pain outcomes observed that $76.4 \%$ experienced back pain that lasted less than a month. ${ }^{14}$

Only $58.7 \%$ of the population with back pain sought treatment. There were several causes for this. Among the respondents with back pain, $60.5 \%$ said that the maximum pain that they experienced was mild. Another, $36.3 \%$ thought that their pain was because of excessive exertion only whereas $15.3 \%$ thought that it was because of lifting heavy weights. But when asked specifically as to what was the cause for not seeking medical treatment, the most common answer(71.3\%) was that the pain was mild and self limiting in nature. The next common answer was that they did not have time. Pradhan A, in her study conducted in Kirtipur, Nepal observed that only $17.5 \%$ of the people with back pain tried to seek medical treatment. The reasons stated by the respondents were that the pain was due to overexertion and long working day and that the doctors could not help as they could not stop working. ${ }^{12}$

Back pain was not a major cause of work days lost. In $81 \%$ of the population, it was less than 5 days.

There are certain shortcomings of this study. First, the study cannot be generalized to the whole of Nepal as the data represent only the population of Eastern Nepal. Second the sample size of the study population was small which could make certain findings statistically insignificant.

\section{Conclusion}

Back pain is a very common complaint among the adult population in the community. Population belonging to 31-50 years age group, married status and farmers and labourers are prone to have back pain. Gender, height and weight are not associated with back pain.

\section{Acknowledgements}

The authors are thankful to all the people who have participated in the study by responding to the questionnaires and the Research Committee of B.P.Koirala Institute of Health Sciences, Dharan.

\section{References}

1. Coste J, Paolaggi JB.Critical review of epidemiology of backache.Rev Epidemiol Sante Publique 1989;37(4):371-83.

2. Hult L. The Munkfors investigation. Acta Orthop Scand Suppl 1954; 16:1.

3. Gilgil E, Kacar C, Butun B,Tuncer T, Urhan S, Yildirim $\mathrm{C}$ et al. Prevalence of low back pain in a developing urban setting. Spine 2005;30(9):1093-8.

4. Kelsey JL, White AA. Epidemiology and impact of low back pain.Spine1980 (2):133-42.

5. Frymoyer JW, Cats-Baril WL. An overview of the incidence and costs of low back pain. Orthop Clin North Am 1991;22(2):263-71

6. Frymoyer JW, Pope MH, Clements JH, et al. Risk factors in low back pain. J Bone Joint Surg Am.1983; 65:213-18.

7. Wong DA, Transfeldt E.Macnab's Backache. $4^{\text {th }}$ ed. Philadelphia:Lippincott Williams and Wilkins; 2007.

8. Deyo RA, Bass JE. Lifestyles and low back pain: the influence of smoking, exercise and obesity. Clin Res 1987; 35:577A.

9. JacekA, Eric CS, John ME. Predictors of Back Pain in a General Population Cohort. Spine 2003;29:70-8.

10. Croft PR, Papageourgiou AC, Thomas E, et al. Short-term physical risk factors for new episodes of low back pain: prospective evidence from the South Manchester Back Pain Study. Spine1999; 24:1556-61.

11. Acharya $M \&$ Bennett $L$. The rural women of Nepal: an aggregate analysis and summary of 8 village studies. Kathmandu: Centre for Economic Development and Administration; 1981.

12. Pradhan A. Backache prevalence among groups with long and normal working day. KUMJ 2003; 2(6):119-23.

13. Kelsey J, White A, Pastides H, Brobee G. The impact of musculoskeletal disorders in the population of United States. J Bone Joint Surg 1979; 61:959-64.

14. Tamar J, Maras B, Aviva Z. A longitudinal, community based study of low back pain outcomes. Spine 2004 ; 29(16):1810-17. 